\title{
PERCEPÇÃO DOS DISCENTES E DOCENTES ACERCA DA HONESTIDADE ACADÊMICA EM UM CURSO DE CIÊNCIAS CONTÁBEIS
}

\author{
PERCEPTION OF INSTRUCTORS AND LEARNERS ABOUT ACADEMIC \\ HONESTY IN AN ACCOUNTING COURSE
}

\author{
Ana Clara Lacerda Oliveira \\ Universidade Federal de Uberlândia - UFU \\ anaclaracontabeis@ hotmail.com \\ Ana Isabel Rocha Assis \\ Universidade Federal de Uberlândia - UFU \\ bel_jti@hotmail.com \\ Denise Mendes da Silva \\ Universidade Federal de Uberlândia - UFU \\ denysemendes03@gmail.com
}

José Dutra de Oliveira Neto Universidade de São Paulo - USP dutra@usp.br

Submissão: 31/07/2013

Aprovação: 30/01/2014

\section{RESUMO}

Os recentes escândalos corporativos trouxeram para o ensino da contabilidade a discussão relativa ao comportamento ético do profissional contábil. As pesquisas sobre honestidade acadêmica podem fomentar não só essa discussão, mas também a preparação do aluno para enfrentar a complexidade do ambiente corporativo. O objetivo deste trabalho é identificar a percepção dos discentes e docentes de um curso de graduação em Ciências Contábeis acerca da honestidade acadêmica. É uma pesquisa descritiva com uma amostra de 17 professores e 469 alunos que analisaram diversos casos com honestidade questionável. Os resultados evidenciam diferenças de percepções entre alunos e professores em relação à honestidade acadêmica e às penalidades aplicáveis a casos percebidos como academicamente desonestos. Tais resultados confirmam as diferenças percebidas em estudos anteriores e indicam que a honestidade acadêmica ainda é um problema no ensino da contabilidade. Assim, a discussão sobre essa temática em sala de aula deve ser incentivada.

Palavras-chave: Honestidade Acadêmica. Ética. Ensino. Contabilidade. 


\begin{abstract}
Recent corporate scandals have brought to the teaching of accounting discussion on the ethical behavior of accounting professionals. Research on academic honesty can foster not only this thread but also the student's preparation to face the complexity of the corporate environment. The objective of this work is to identify the perceptions of students and instructors of an undergraduate course in Accounting regarding academic honesty. A descriptive research with a sample of 17 instructors and 469 students who analyzed several cases with questionable honesty. The results show differences in perceptions between instructors and students regarding academic honesty and penalties applicable to cases perceived as academically dishonest. These results confirm the perceived differences in previous studies and indicate that academic honesty is still a problem in accounting education. Thus, the discussion on this topic in the classroom should be encouraged.
\end{abstract}

Keywords: Academic Honesty. Ethics. Teaching. Accounting. 


\section{INTRODUÇÃO}

Nos últimos anos observa-se um aumento das pesquisas relacionadas ao tema honestidade acadêmica, tanto no exterior (JONHS; STRAND, 2000; SIMON et al., 2004; BRAUN; STALLWORTH; CRAM, 2005) como no Brasil (BARBASTEFANO; SOUZA, 2007; SILVA, 2008; OLIVEIRA NETO; CHACAROLLI, 2010). A honestidade acadêmica é parte integrante do código de ética das instituições de ensino. As pesquisas internacionais analisaram respondentes das áreas de contabilidade e química, porém apenas a última pesquisa mencionada envolveu os professores. Já os estudos brasileiros focaram o plágio acadêmico e suas amostras englobaram respondentes das áreas de contabilidade e engenharia. As duas primeiras pesquisas citadas são empíricas e não envolvem casos potenciais de desonestidade, além de não incluírem professores na amostra.

Alguns questionamentos que surgiram nesses estudos estão relacionados não só à percepção dos alunos mas também à dos professores a respeito de comportamentos considerados academicamente desonestos, ao que pode motivar a desonestidade acadêmica e se esses comportamentos na academia podem afetar a atuação profissional. É sabido que todos os profissionais devem seguir o código de ética, ou seja, um conjunto de diretrizes para atitudes consideradas ideais e morais no exercício da profissão. Crown e Spiller (1998), em uma revisão de 25 anos da literatura acerca da desonestidade acadêmica, evidenciaram que o comportamento acadêmico pode contribuir para o melhor conhecimento acerca da ética profissional. Nonis e Swift (2001) evidenciaram, em uma amostra com 1.051 alunos, oriundos da área de negócios, que os estudantes com comportamentos academicamente desonestos têm maior probabilidade de repetir o comportamento no ambiente de trabalho.

Nesse contexto, surge o seguinte questionamento: existem diferenças na percepção dos discentes e docentes de um curso de graduação em Ciências Contábeis acerca da honestidade acadêmica? Assim, o objetivo deste trabalho é identificar a percepção dos discentes e docentes de um curso de graduação em Ciências Contábeis acerca da honestidade acadêmica.

Oliveira Neto e Chacarolli (2010) realizaram pesquisa semelhante com 102 estudantes e 12 professores em um curso de contabilidade de uma universidade pública brasileira, situada no estado de São Paulo. O presente estudo procura confirmar se os resultados encontrados por Oliveira Neto e Chacarolli (2010) são consistentes para uma amostra de alunos do estado de Minas Gerais. Essa pesquisa, além de abranger uma amostra maior em um estado diferente, 
investiga se os fatores, como gênero e idade, influenciam as avaliações acerca da honestidade acadêmica.

O estado de Minas Gerais foi foco dessa pesquisa, pois concentra grande quantidade de cursos superiores em Ciências Contábeis e, também, grande número de profissionais contábeis. Uma consulta realizada em 25 de fevereiro de 2013 no portal eletrônico do Ministério da Educação (BRASIL, 2013) revelou existir, nessa data, 1.277 cursos superiores em Ciências Contábeis ativos no Brasil, tanto na modalidade presencial como a distância, dos quais 147 se localizam em Minas Gerais, ou seja, 11,5\%. Minas Gerais é, também, o terceiro maior estado em número de contadores registrados, totalizando 24.199 profissionais em 31 de outubro de 2010, conforme dados disponíveis no portal do Conselho Federal de Contabilidade (2013), ficando atrás, apenas, de São Paulo e Rio de Janeiro, que ocupam, respectivamente, o primeiro e o segundo lugar.

O presente estudo é importante por discutir uma característica requerida no comportamento pessoal, acadêmico e profissional, que é a honestidade. No caso dos alunos de negócios e, mais especificamente, dos alunos de Contabilidade, espera-se uma atuação fortemente consistente com princípios morais e éticos, tendo em vista as competências e habilidades a eles atribuídas para desempenho de suas funções. Resta saber se essa expectativa se alinha à percepção que esses estudantes e seus professores têm em relação ao comportamento academicamente honesto e quais penalidades poderiam ser impostas para casos percebidos como desonestos.

Este trabalho está dividido em cinco seções, incluindo-se esta introdução. $\mathrm{Na}$ sequência encontram-se a revisão da literatura que fundamenta as discussões, os aspectos metodológicos que possibilitam a coleta e análise dos dados, a apresentação e análise dos resultados e, por fim, a conclusão.

\section{REVISÃO DA LITERATURA}

Para melhor compreensão, esta seção foi dividida em duas subseções. Na primeira subseção apresentam-se os conceitos de ética geral e profissional, incluindo-se a profissão contábil e o relacionamento desses conceitos com a desonestidade acadêmica. A segunda subseção aborda estudos anteriores sobre o tema honestidade e desonestidade no meio acadêmico. 


\section{1 Ética e desonestidade acadêmica}

Vásquez (1987) afirma que a ética é a ciência do comportamento humano em sociedade, ou seja, apresenta caráter científico. Como ciência, ela tem um objeto próprio: o agir moral humano e, embora parta de evidências empíricas, a ética não permanece na simples descrição dos fatos, mas elabora conceitos e teorias. Por isso, suas proposições devem ter rigor, coerência e fundamentação, como acontece com as proposições científicas. Uma visão diferente é dada por Bittar (2007), que explica que a ética também é reconhecida como uma filosofia prática, cujo conteúdo é o agir humano. Nessa perspectiva, defini-la como ciência seria restringir a amplitude das discussões que contempla, pois seu conteúdo é ilimitado, uma vez que as ações humanas também o são.

A ética liga-se a toda prática humana, seja ela profissional ou não e, para toda atividade profissional, existe, ou deveria existir, uma ética aplicada a ela (ANJOS et al., 2011). A ética profissional é a aplicação da ética geral nas atividades profissionais (CAMARGO, 1999). Borges e Medeiros (2007) afirmam, nesse sentido, que ser ético dentro da profissão significa esquecer a parte e pensar no conjunto, fomentando-se, assim, um crescimento coletivo. Segundo Fortes (2005), a conduta dos profissionais precisa ser sempre pautada pela honestidade e dignidade, de forma que essas qualidades se transformem em diferencial e lhes confiram autoridade moral. Alinhado com essas perspectivas, visualiza-se a honestidade e a moral dentro de um conceito maior que é o da ética.

Quando se trata de ética profissional, aborda-se, também, o código de ética das diversas categorias. Para Lisboa et al. (1997), um dos objetivos da existência de um código de ética é auxiliar na formação ética, na constituição de uma consciência sobre regras e padrões de conduta. No caso do profissional contábil, seu comportamento é regulado pelo Código de Ética do Profissional Contabilista, aprovado pela Resolução n. 803/1996 do Conselho Federal de Contabilidade. Fortes (2005), tratando da ética do profissional da Contabilidade, diz que as normas existem para serem cumpridas e aqueles que não as cumprirem poderão sofrer as penalidades previstas na Resolução CFC n. ${ }^{\circ}$ 949/2002, que traz o Regulamento de Procedimentos Processuais dos Conselhos de Contabilidade, no Capítulo X, art. 58.

Anjos et al. (2011, p. 4) destacam: 
O profissional contábil, de tempos em tempos, recebe críticas das mais diversas áreas da sociedade, que reclama de seu comportamento frente a dilemas éticos, e por vezes o contador é demonstrado (através de comentários, reportagens, filmes, novelas e até mesmo charges) como alguém que não se preocupa com virtudes morais.

Para tentar minimizar esse problema, uma estratégia seria entender melhor o comportamento dos futuros profissionais contábeis ainda dentro das escolas e procurar compreender como os alunos e professores lidam com questões éticas e comportamentos desonestos no ambiente acadêmico.

Lambert, Hogan e Barton (2003) definem desonestidade acadêmica como quaisquer ações fraudulentas ou tentativas por um aluno de usar meios não autorizados ou inaceitáveis em qualquer trabalho acadêmico. De acordo com Pavela (1978) existem quatro áreas gerais que compõem a desonestidade acadêmica: 1) usar materiais não autorizados em qualquer atividade acadêmica; 2) fabricar informações, referências ou resultados; 3) plagiar; 4) auxiliar outros estudantes a se envolverem com desonestidade acadêmica, como, por exemplo, permitir que copiem seu trabalho, manter bancos de testes, memorizar questões em uma avaliação etc.

Segundo Cavalcanti (2008), a desonestidade acadêmica, tão comum nos ambientes educacionais, pode ser definida como a quebra de normas acadêmicas da instituição educacional que estabelece as regras de comportamento de professores e alunos. De acordo com a autora, muitas instituições determinam, nesse documento, as ações que são consideradas inaceitáveis, como, por exemplo, cola em provas, trabalhos e projetos escolares; falsificação de documentos ou dados; apresentação de trabalhos elaborados por terceiros ou copiados de fontes não citadas.

Com o aumento do uso da tecnologia nos processos educacionais, aumentam, também, as chances de comportamentos desonestos, notadamente o plágio, que consiste em "apropriação de linguagem e de ideias do outro, caracterizando violação da propriedade intelectual" (SILVA, 2008, p. 358). Barbastefano e Souza (2007) apontam algumas razões para a prática do plágio, como desconhecimento de legislação, facilidade de obtenção de trabalhos e incapacidade de parafrasear por parte dos autores. Relatam, também, que medidas, como divulgação de regras, mudança de tipos de trabalho, uso de ferramentas de busca para identificar plágio e identificações de padrões de texto, podem combater o plágio acadêmico.

A desonestidade acadêmica tem despertado o interesse de estudiosos de forma crescente nas últimas décadas, sendo tema de muitos trabalhos no exterior e no Brasil e em 
diversas áreas do conhecimento, como pode ser visto nas discussões a seguir. Ashworth e Bannister (1997) afirmam que compreender a perspectiva do estudante sobre o uso de fraudes e plágio pode auxiliar, significativamente, acadêmicos em seus esforços para comunicar as normas adequadas.

\subsection{Estudos anteriores}

As pesquisas sobre desonestidade acadêmica buscam compreender aspectos relacionados à ética, fraude, percepções dos alunos e professores com relação à desonestidade no meio acadêmico, motivações para comportamentos academicamente desonestos e a relação desses comportamentos com a atuação profissional no mercado de trabalho.

Newstead, Franklyn-Stokes e Armstead (1996) tiveram como principal objetivo investigar as causas e incidências de fraudes no meio acadêmico, utilizando um questionário distribuído aos estudantes em uma universidade inglesa. Os entrevistados foram convidados a indicar, confidencialmente, quais comportamentos eles realizaram na universidade. Ao total, 943 estudantes responderam ao questionário. Os resultados apontaram que as fraudes foram mais comuns em homens do que mulheres, com os alunos menos capazes do que com os mais capazes, mais comuns em alunos jovens do que em alunos maduros e mais comuns em estudantes de ciências e tecnologia do que de outras disciplinas.

Smith, Nolan e Dai (1998) investigaram a percepção dos estudantes e professores sobre a honestidade acadêmica, por meio de questionários enviados aos dois grupos. Participaram da pesquisa 160 estudantes de graduação e 50 professores. Os resultados mostraram que, embora algumas das respostas dos professores e alunos tenham sido semelhantes, as percepções dos professores em relação ao comportamento dos alunos foram mais negativas do que o relatado pelos alunos. Os pesquisadores sugeriram que os alunos responderam às perguntas de acordo com seu próprio sistema de crenças, porém os professores podem ter respondido com base em sua experiência com o comportamento dos alunos.

Johns e Strand (2000) realizaram um estudo com 581 alunos de cursos na área de negócios (marketing, economia, contabilidade e administração) de quatro universidades, no intuito de responder à seguinte questão: quais são as crenças e atitudes dos estudantes de negócios de hoje, que serão os líderes empresariais do futuro? Os resultados mostraram que os comportamentos que os estudantes da área de negócios acreditam ser mais antiéticos foram: 
fazer um teste para alguém e obter respostas de alguém durante um exame. Já os comportamentos menos antiéticos na visão dos estudantes pesquisados foram: estudar a partir das anotações de outras pessoas e deixar de relatar erros desfavoráveis na classificação (pontuação obtida). A cada nova classe de estudantes universitários, os educadores devem lembrar-se de que o problema nunca é resolvido, ou seja, com relação à conduta ética ainda há muito a melhorar (JOHNS; STRAND, 2000).

A pesquisa de Simon et al. (2004) foi realizada em quinze cursos de graduação em química na Universidade de Nevada. Os resultados dessa pesquisa confirmaram o que a literatura defende: há uma diferença entre os sexos em termos de perspectivas institucionais. Os autores verificaram que as alunas levam seu estudo mais a sério, porém indicaram que a universidade não sabe lidar com o comportamento desonesto, enquanto os alunos são menos preocupados com o comportamento desonesto e não estão dispostos a ajudar para o fim desse comportamento. No total, apenas $35,7 \%$ dos estudantes indicaram que eles relatariam um caso de suspeita de desonestidade acadêmica, mas, segundo o estudo, quase $46 \%$ das alunas iriam relatar, enquanto menos de $30 \%$ dos alunos relatariam um caso.

Cavalcanti (2008) teve como objetivo apresentar considerações advindas de uma investigação bibliográfica, com o intuito de apontar e discutir aspectos relacionados à desonestidade acadêmica em cursos superiores à distância. Concluiu que, no meio educacional, presencial e a distância, muitas vezes os valores éticos e morais são atropelados pelo desejo desenfreado de obter resultados excelentes, mesmo que seja por meio da desonestidade acadêmica.

Braun, Stallworth e Cram (2005) analisaram as percepções de 458 estudantes e 177 professores de contabilidade a respeito da honestidade acadêmica, por meio de um questionário envolvendo casos potenciais de desonestidade acadêmica, bem como as penalidades que poderiam ser atribuídas a cada caso considerado academicamente desonesto. Os resultados indicaram que alunos e professores veem situações que envolvem honestidade acadêmica de forma diferente, o que implica a existência de uma lacuna na expectativa de ambos sobre esse tema e, também, que ambos são conscientes dessa diferença de visão. Os resultados indicaram, adicionalmente, que não houve diferenças significativas entre alunos e professores sobre os comportamentos que eram mais claramente honestos ou desonestos. A maior diferença existe para "zona cinzenta”, que engloba casos não claramente honestos ou desonestos. 
No Brasil, Oliveira Neto e Chacarolli (2010) reaplicaram a pesquisa de Braun, Stallworth e Cram (2005). O questionário, com ligeiras adaptações, foi aplicado a 102 alunos de contabilidade e 12 professores, em uma universidade pública paulista. Tanto os alunos, como os professores analisaram os comportamentos descritos em todos os casos e atribuíram as penalidades que deveriam ser aplicadas em cada caso considerado academicamente desonesto. Os resultados evidenciaram que a visão dos alunos e dos professores envolvendo honestidade acadêmica é diferente apenas para os casos "cinzentos". Nos demais casos, existe um alinhamento entre a visão dos alunos e professores na escola pesquisada, o que contraria os resultados da pesquisa original americana.

Em linha com os questionamentos da literatura pesquisada acerca das diferentes visões dos alunos e professores sobre a honestidade acadêmica, surgem as hipóteses desta pesquisa, como se pode verificar no Quadro 1.

\section{Quadro1 - Questões de pesquisa e suas hipóteses (Continua)}

\begin{tabular}{|c|c|c|c|}
\hline \multicolumn{2}{|r|}{ Questões de pesquisa } & Hipóteses - Honestidade & \multirow[b]{2}{*}{$\begin{array}{l}\text { Hipóteses - Penalidade } \\
\text { H1 - Penalidade: Os professores irão } \\
\text { adotar, em situações envolvendo } \\
\text { comportamentos } \\
\text { questionáveis, penalidades mais } \\
\text { severas do que as penalidades } \\
\text { impostas pelos alunos. }\end{array}$} \\
\hline 1 & $\begin{array}{l}\text { Existem diferenças entre as } \\
\text { avaliações de alunos e professores, } \\
\text { em relação à honestidade } \\
\text { acadêmica? }\end{array}$ & $\begin{array}{l}\text { H1 - Honestidade: Os professores irão } \\
\text { classificar as situações, envolvendo } \\
\text { comportamentos acadêmicos questionáveis, } \\
\text { como sendo mais severos que a avaliação } \\
\text { feita pelos alunos. }\end{array}$ & \\
\hline $2^{\mathrm{a}}$ & $\begin{array}{l}\text { Os alunos percebem que existe } \\
\text { uma diferença entre a avaliação dos } \\
\text { alunos, em relação à honestidade } \\
\text { acadêmica, e a avaliação do } \\
\text { professor na visão dos alunos para } \\
\text { o mesmo caso? }\end{array}$ & $\begin{array}{l}\mathrm{H} 2 \mathrm{a} \text { - Honestidade Aluno: As avaliações } \\
\text { realizadas pelos alunos serão menos } \\
\text { rigorosas que as avaliações dos professores } \\
\text { na visão dos alunos. }\end{array}$ & $\begin{array}{l}\text { H2a - Penalidade Aluno: As } \\
\text { penalidades impostas pelos alunos } \\
\text { serão menos rigorosas que as } \\
\text { penalidades dos professores na visão } \\
\text { dos alunos. }\end{array}$ \\
\hline $2 b$ & $\begin{array}{l}\text { Os professores percebem que } \\
\text { existe uma diferença entre a } \\
\text { avaliação dos professores, em } \\
\text { relação à honestidade acadêmica, e } \\
\text { a avaliação dos alunos na visão do } \\
\text { professor para o mesmo caso? }\end{array}$ & $\begin{array}{l}\text { H2b - Honestidade Professor: As avaliações } \\
\text { realizadas pelos professores serão mais } \\
\text { rigorosas que as avaliações dos alunos na } \\
\text { visão dos professores. }\end{array}$ & $\begin{array}{l}\mathrm{H} 2 \mathrm{~b} \text { - Penalidade Professor: As } \\
\text { penalidades impostas pelos } \\
\text { professores serão mais rigorosas que } \\
\text { as penalidades dos alunos na visão } \\
\text { dos professores. }\end{array}$ \\
\hline $3^{\mathrm{a}}$ & $\begin{array}{l}\text { As percepções dos alunos em } \\
\text { relação às avaliações realizadas } \\
\text { pelos professores são precisas? }\end{array}$ & $\begin{array}{l}\text { H3a - Honestidade Aluno: Os alunos irão } \\
\text { perceber as avaliações dos professores, em } \\
\text { relação à honestidade acadêmica, como } \\
\text { sendo mais rigorosas do que elas realmente } \\
\text { são. }\end{array}$ & - \\
\hline $3 b$ & $\begin{array}{l}\text { As percepções dos professores em } \\
\text { relação às avaliações realizadas } \\
\text { pelos alunos são precisas? }\end{array}$ & $\begin{array}{l}\text { H3b - Honestidade Professor: Os professores } \\
\text { irão perceber as avaliações dos alunos, em } \\
\text { relação à honestidade acadêmica, como } \\
\text { sendo menos rigorosas do que elas realmente } \\
\text { são. }\end{array}$ & - \\
\hline $4^{\mathrm{a}}$ & $\begin{array}{l}\text { Existem diferenças entre as } \\
\text { avaliações de alunos, em relação à } \\
\text { honestidade acadêmica, } \\
\text { considerando apenas o gênero? }\end{array}$ & $\begin{array}{l}\text { H4a - gênero aluno: As alunas irão } \\
\text { classificar as situações, envolvendo } \\
\text { comportamentos acadêmicos questionáveis, } \\
\text { como sendo mais severas que a avaliação } \\
\text { feita pelos alunos. }\end{array}$ & - \\
\hline $4 \mathrm{~b}$ & $\begin{array}{l}\text { Existem diferenças entre as } \\
\text { avaliações de professores, em } \\
\text { relação à honestidade acadêmica, } \\
\text { considerando apenas o gênero? }\end{array}$ & $\begin{array}{l}\text { H4b - gênero professor: As professoras irão } \\
\text { classificar as situações, envolvendo } \\
\text { comportamentos acadêmicos questionáveis, } \\
\text { como sendo mais severas que a avaliação } \\
\text { feita pelos professores. }\end{array}$ & - \\
\hline
\end{tabular}




\begin{tabular}{|l|l|l|l|}
\hline $5^{\mathrm{a}}$ & $\begin{array}{l}\text { Existem diferenças entre as } \\
\text { avaliações de alunos, em relação à } \\
\text { honestidade acadêmica, } \\
\text { considerando apenas a idade? }\end{array}$ & $\begin{array}{l}\text { H5a - idade aluno: Os alunos (ambos os } \\
\text { gêneros) com maior idade irão classificar as } \\
\text { situações, envolvendo comportamentos } \\
\text { acadêmicos questionáveis, como sendo mais } \\
\text { desonestas que a avaliação feita pelos alunos } \\
\text { de menor idade. }\end{array}$ & - \\
\hline $5 b$ & $\begin{array}{l}\text { Existem diferenças entre as } \\
\text { avaliações de professores, em } \\
\text { relação à honestidade acadêmica, } \\
\text { considerando apenas a idade? }\end{array}$ & $\begin{array}{l}\text { H5b - idade professor: Os professores } \\
\text { (ambos os gêneros) com maior idade irão } \\
\text { classificar as situações, envolvendo } \\
\text { comportamentos acadêmicos questionáveis, } \\
\text { como sendo mais desonestas que a avaliação } \\
\text { feita pelos professores de menor idade. }\end{array}$ & \\
\hline
\end{tabular}

Quadro1 - Questões de pesquisa e suas hipóteses (Continuação)

\begin{tabular}{|c|l|l|c|}
\hline \multicolumn{2}{|c|}{ Questões de pesquisa } & \multicolumn{1}{|c|}{ Hipóteses - Honestidade } & Hipóteses - Penalidade \\
\hline 6 & As diferenças na expectativa dos & H6 - Não uniformidade: As diferenças na & \\
& professores e alunos, em relação à & avaliação da honestidade acadêmica são & \\
honestidade acadêmica, são uniformes & mais prováveis de acontecer nas situações & \\
em todas as situações? & que envolvem casos cinzentos. As & \\
& diferenças são menos prováveis de & \\
& acontecer em situações de & \\
& comportamentos claramente honestos e & \\
& claramente desonestos. & \\
\hline
\end{tabular}

Fonte: Elaborado pelos autores deste artigo.

Alinhado com Braun, Stallworth e Cram (2005) e Oliveira Neto e Chacarolli (2010), o presente trabalho deseja identificar a percepção dos discentes e docentes de um curso de graduação em Ciências Contábeis de uma universidade pública federal mineira acerca da honestidade acadêmica. Considerando-se que as diferenças regionais podem impactar os resultados das percepções dos alunos e professores, acredita-se que a pesquisa possa trazer contribuições sobre as percepções dos alunos e professores em diversas regiões do Brasil. Há uma expectativa, também, de que a reflexão sobre este assunto possa contribuir para a formação ética do profissional contábil.

\section{ASPECTOS METODOLÓGICOS}

\subsection{Classificação da pesquisa}

Quanto aos objetivos, esta pesquisa classifica-se como descritiva, cujo principal objetivo, segundo Gil (2006), é descrever as características de certa população, fenômeno ou estabelecer relações entre variáveis. Incluem-se, também nessa classificação, os estudos que objetivam levantar opiniões, atitudes e crenças de certa população. Para se utilizar dessa técnica, padroniza-se a coleta de dados, o que pode ser realizado por meio de observação sistemática e questionário. 
No que diz respeito à abordagem do problema, é quantitativa. Para Martins e Theóphilo (2007), na abordagem quantitativa, busca-se explicar fatos e situações por meio de medições, tendo-se uma perspectiva externa.

Quanto aos procedimentos técnicos utiliza-se do levantamento, que segundo Gil (2006), tem como principal objetivo traçar um conceito abstrato com relação a determinado grupo. 


\subsection{Procedimentos de coleta e análise de dados}

Os dados foram coletados por meio de dois questionários, em que alunos e professores responderam sobre casos envolvendo situações de potencial desonestidade acadêmica e ainda foi solicitado que estes sugerissem as penalidades que deveriam ser aplicadas em cada situação. Os questionários são baseados no estudo de Oliveira Neto e Chacarolli (2010), com pequenas alterações em que a principal diz respeito à exclusão de questões abertas. Pelo fato de se terem realizado essas alterações, os questionários foram submetidos a um pré-teste com dez alunos e seis professores a fim de eliminar eventuais dificuldades de compreensão.

Aos alunos foi questionada a percepção deles de como os professores reagiriam em cada situação, assim como aos professores foi questionada a percepção deles sobre como os alunos reagiriam. Tal procedimento visa eliminar um possível viés na pesquisa, já que, ao avaliar seu próprio comportamento, o participante poderia se sentir intimidado, comprometendo os resultados.

Os dados foram coletados no mês de janeiro de 2013. Os questionários foram aplicados aos alunos do primeiro ao décimo período (turno integral e noturno) do curso de Ciências Contábeis de uma universidade pública federal do estado de Minas Gerais e aos professores do mesmo curso. A coleta com os alunos foi feita por meio de questionários impressos, aplicados em sala de aula. Aos professores que ministram aulas no referido curso o questionário foi aplicado em suas respectivas salas de trabalho.

Participaram da pesquisa 469 alunos, correspondentes a 57\% dos alunos ativos no curso na época da pesquisa, e 17 professores, equivalentes a 60,7\% dos professores que ministravam aulas no curso nessa mesma época. As informações demográficas dos alunos e professores componentes da amostra são apresentadas nas Tabelas 1 e 2, respectivamente. 
Tabela 1 - Informações demográficas dos alunos

\begin{tabular}{|c|c|c|}
\hline Característica & Categoria & Percentual \\
\hline \multirow{3}{*}{ Gênero } & Feminino & 56,9 \\
\hline & Masculino & 41,8 \\
\hline & Sem reposta & 1,3 \\
\hline \multirow{3}{*}{ Idade } & Tradicional (17-25) & 87,4 \\
\hline & Não-tradicional (26+) & 11,7 \\
\hline & Sem resposta & 0,9 \\
\hline \multirow{6}{*}{ Ano } & $1^{\mathrm{o}}$ ano & 24,5 \\
\hline & $2^{\mathrm{o}}$ ano & 20,6 \\
\hline & $3^{\mathrm{o}}$ ano & 24,2 \\
\hline & $4^{\mathrm{o}}$ ano & 18,1 \\
\hline & $5^{\mathrm{o}}$ ano & 9,4 \\
\hline & Sem resposta & 3,2 \\
\hline \multirow[b]{2}{*}{ Turno } & Integral & 38,6 \\
\hline & Noturno & 61,4 \\
\hline \multirow{3}{*}{ Trabalha ou trabalhou na área contábil? } & Sim & 39,0 \\
\hline & Não & 60,0 \\
\hline & Sem resposta & 1,0 \\
\hline
\end{tabular}

Nota: $\mathrm{n}=469$.

Fonte: Elaborado pelos autores deste artigo.

Tabela 2 - Informações demográficas dos professores

\begin{tabular}{lll}
\hline Característica & Categoria & Percentual \\
\hline Gênero & Feminino & 47,1 \\
& Masculino & 52,9 \\
Idade & Menos que 35 & 11,8 \\
& $35-45$ & 58,8 \\
& $46-50$ & 11,8 \\
& Acima de 50 & 17,6 \\
Titulação & Mestre & 58,8 \\
& Doutor & 41,2 \\
\hline
\end{tabular}

Nota: $\mathrm{n}=17$.

Fonte: Elaborado pelos autores deste artigo.

O questionário desenvolvido coleta informações acerca da honestidade e penalidade acadêmica. O termo honestidade acadêmica refere-se à aderência por parte dos discentes e docentes aos princípios acadêmicos morais e éticos da instituição. Diversos atos acadêmicos constituem violações à honestidade acadêmica: plágio, cola, falsificação, cumplicidade, mal uso de materiais acadêmicos entre outros. Já a penalidade, corresponde às sanções propostas à violação da honestidade acadêmica.

Para avaliação das situações descritas nos questionários foi utilizada uma escala que vai de -2 (comportamento academicamente desonesto) até 2 (comportamento academicamente honesto). Para as penalidades foi utilizada a escala Likert de cinco pontos, em que 1 
corresponde a nenhuma penalidade e 5 é a penalidade máxima da instituição. Os casos utilizados na pesquisa foram: (A) Passar informação de exames já realizados com dois casos: (A1) Caso cinzento (Ana e Luís) e (A2) Caso claramente desonesto (Edson e Breno); (B) Trabalho em grupo com dois casos: (B1) Caso cinzento (Diego) e (B2) Caso claramente honesto (José); (C) Adequação da citação com dois casos: (C1) Caso cinzento (Henrique) e (C2) Caso claramente honesto (Paulo) e (D) Submissão de uma tarefa não inédita com dois casos: (D1) Caso cinzento (André) e (D2) Caso claramente desonesto (Patrícia). Os "casos cinzentos" referem-se a casos que não se enquadram em "claramente honesto ou desonesto".

Os dados foram submetidos a análises estatísticas e as hipóteses foram testadas por meio de testes não paramétricos, como o teste de Mann-Whitney, para analisar as duas amostras no intuito de comparar a mediana entre os dois grupos, e o teste não paramétrico de Wilcoxon para amostras pareadas, para comparar a opinião dos sujeitos em relação à percepção da opinião do outro grupo. A próxima seção apresenta os resultados obtidos.

\section{APRESENTAÇÃO E ANÁLISE DOS RESULTADOS}

A discussão inicia-se com a existência ou não de diferenças entre as avaliações dos alunos e professores a respeito da honestidade acadêmica, seguida das percepções acerca dessas diferenças e a precisão dessa percepção. Para finalizar, é discutido o efeito do gênero e da idade na amostra pesquisada.

\subsection{Existência de diferenças nas avaliações realizadas pelos alunos e professores acerca da honestidade acadêmica}

Considerando-se que cada instituição possui um código de ética que deve nortear as atividades acadêmicas, surge a primeira pergunta: será que os alunos e professores estão alinhados com a honestidade acadêmica? Para identificar se existem diferenças de percepção em relação à honestidade acadêmica entre professores e alunos, as respostas dos alunos para cada situação foram comparadas com as respostas correspondentes dos professores. Os resultados foram obtidos por meio das diferenças entre a avaliação dos alunos e professores com o teste não paramétrico de Mann-Whitney para amostras independentes com $p \leq 0,05$ para os oito casos presentes na pesquisa, conforme Tabela 3 . 
Tabela 3 - Diferenças entre avaliação dos alunos e professores

\begin{tabular}{lcc}
\hline Casos & $\mathbf{Z}$ & $\mathbf{p}$ \\
\hline (A) Passar informação de exames já realizados & &, $060^{*}$ \\
(A1) Caso cinzento (Ana e Luís) & $-1,883$ &, 376 \\
(A2) Caso claramente desonesto (Edson e Breno) &,- 885 & \\
& &, 000 \\
(B) Trabalho em grupo & $-3,791$ &, 121 \\
$\quad$ (B1) Caso cinzento (Diego) - p < 0,001 & $-1,552$ & \\
(B2) Caso claramente honesto (José) & &, 000 \\
& $-3,594$ &, 361 \\
(C) Adequação da citação &,- 914 & \\
(C1) Caso cinzento (Henrique) - p < 0,001 & & \\
(C2) Caso claramente honesto (Paulo) & $-4,511$ &, 000 \\
(D) Submissão de uma tarefa não inédita & $-1,379$ &, 168 \\
(D1) Caso cinzento (André) - p < 0,001 & & \\
(D2) Caso claramente desonesto (Patrícia)
\end{tabular}
Notas: Avaliação da Honestidade $(-2=$ Desonesto; 2 = Honesto); * Valor muito próximo do nível de significância adotado $\mathrm{p}=0,05$.

Fonte: Elaborado pelos autores deste artigo com dados da pesquisa.

As diferenças estatisticamente significantes foram encontradas em apenas três dos oito casos. Esse resultado é inconsistente com a hipótese H1 - Honestidade, que diz que os professores classificarão as situações envolvendo comportamentos acadêmicos questionáveis como sendo mais rigorosos que a avaliação feita pelos alunos, e difere do trabalho americano, de Braun, Stallworth e Cram (2005), e do brasileiro, de Oliveira Neto e Chacarolli (2010), em que a existência de uma diferença significativa na avaliação realizada pelos alunos ocorreu em 2 e 5 dos oito casos, respectivamente.

Ao analisar-se por categorias de casos (claramente honesto, cinzento e claramente desonesto), observa-se que ocorreram diferenças significativas nos casos cinzentos B1, C1 e D1. Nesses casos, os alunos apresentaram valores superiores, o que significa que avaliaram o comportamento como sendo mais honesto que os professores. Em suma, os professores são mais rigorosos que os alunos. Para os casos claramente honestos e claramente desonestos, não se pode afirmar que existam diferenças significativas entre os alunos e professores. Esses resultados são consistentes com a hipótese $H 6$ - Não uniformidade, que propõe que existem diferenças para os casos em que ocorrem as situações cinzentas e o contrário para as demais categorias. Esses resultados são consistentes também com os encontrados por Braun, Stallworth e Cram (2005).

Já para a penalidade, obtiveram-se quatro dos dez casos com diferenças significativas, como mostra a Tabela 4. Em todos os casos em que ocorreu a diferença significativa, os professores apresentaram valores superiores em relação à penalidade em comparação com os 
alunos. Valores superiores significam que os professores são mais severos que os alunos. Os resultados foram obtidos por meio das diferenças entre a penalidade dos alunos versus a penalidade dos professores, com uso do teste não paramétrico de Mann-Whitney para amostras independentes com $\mathrm{p} \leq 0,05$ para os casos presentes na pesquisa. Esse resultado é inconsistente com a hipótese $H 1$ - Penalidade, em que os professores adotarão, em situações envolvendo comportamentos acadêmicos questionáveis, penalidades mais rigorosas do que a penalidade imposta pelos alunos, e é consistente com os trabalhos pesquisados (BRAUN, STALLWORTH; CRAM, 2005; OLIVEIRA NETO; CHACAROLLI, 2010).

Tabela 4 - Diferenças entre a penalidade dos alunos versus penalidade dos professores

\begin{tabular}{lrr}
\hline Casos & $\mathbf{Z}$ & $\mathbf{p}$ \\
\hline (A) Passar informação de exames já realizados &,- 374 &, 708 \\
(A1) Caso cinzento (Ana) &,- 305 &, 760 \\
(A2) Caso cinzento (Luís) &, 000 &, 999 \\
(A3) Caso claramente desonesto (Edson) &,- 522 &, 602 \\
(A4) Caso claramente desonesto (Breno) &, 000 \\
& &, 008 \\
(B) Trabalho em grupo & $-4,909$ & $-2,640$ \\
(B1) Caso cinzento (Diego) &, 004 \\
(B2) Caso claramente honesto (José) &, 600 \\
& $-2,871$ &,- 525 \\
(C) Adequação da citação & &, 000 \\
(C1) Caso cinzento (Henrique) &, 093 \\
(C2) Caso claramente honesto (Paulo) & $-3,893$ \\
(D) Submissão de uma tarefa não inédita & $-1,682$ & \\
(D1) Caso cinzento (André) & & \\
(D2) Caso claramente desonesto (Patrícia) & & \\
\hline
\end{tabular}

Nota: Penalidade $(1=$ Sem penalidade; 5 = Penalidade severa $)$

Fonte: Elaborado pelos autores deste artigo com dados da pesquisa.

\subsection{Percepções da existência de diferenças nas avaliações realizadas pelos alunos e professores acerca da honestidade acadêmica}

A percepção da existência de diferenças entre alunos e professores pode impactar a capacitação dos alunos em relação à honestidade acadêmica. Com uma forma de comunicação eficaz sobre o código de ética da instituição, é possível ajudar a compreensão da ética acadêmica diminuindo a diferença de percepção da avaliação e punição por parte dos professores e alunos. Se o professor segue o código de ética da instituição e o aluno conhece 
como o professor avalia e pune, tem-se uma comunicação acadêmica mais transparente e clara, evitando-se muitos conflitos éticos acadêmicos existentes.

Nessa etapa verifica-se se o aluno tem ideia de como os professores avaliam o mesmo caso (aluno-professor). Os resultados mostraram que existem diferenças significativas entre a avaliação do próprio aluno e a avaliação do professor na visão do aluno para sete dos oito casos em discussão (Tabela 5). Os alunos acreditam que o professor tenha uma opinião diferente do aluno na maior parte dos casos. Em todos os casos com diferenças significativas, a avaliação dos alunos foi maior que a avaliação dos professores na visão do aluno. A avaliação com menor valor na escala Likert significa que o aluno acredita que o professor vai classificar o caso como menos honesto que o aluno. Os alunos acham que o professor será mais severo que eles mesmos em relação à avaliação da honestidade. Os resultados foram obtidos por meio das diferenças entre a avaliação dos alunos e avaliação dos professores na visão dos alunos usando o teste não paramétrico de Wilcoxon para amostras pareadas com $\mathrm{p} \leq$ 0,05 para os oito casos presentes na pesquisa. Esses resultados são consistentes com a hipótese $H 2 a$ - Honestidade aluno, em que as avaliações realizadas pelos alunos serão menos rigorosas que as avaliações dos professores na visão do aluno.

Ao se analisarem as categorias, observou-se que as médias foram significativamente diferentes para todos os quatro casos envolvendo as áreas cinzentas, denotando a existência de diferenças para essas categorias. Os resultados são similares com o trabalho brasileiro pesquisado, com seis dos oito casos significativos, e do original americano, em que, em todas as situações, foram observadas diferenças significativas.

Tabela 5 - Diferenças entre avaliação dos alunos versus avaliação dos professores na visão dos alunos

\begin{tabular}{lrr}
\hline Casos & $\mathbf{Z}$ & $\mathbf{p}$ \\
\hline (A) Passar informação de exames já realizados & &, 000 \\
(A1) Caso cinzento (Ana e Luís) & 12,167 &, 000 \\
(A2) Caso claramente desonesto (Edson e Breno) & $-5,204$ & \\
& &, 000 \\
(B) Trabalho em grupo & $-8,207$ &, 000 \\
(B1) Caso cinzento (Diego) - p < 0,001 & $-5,488$ \\
(B2) Caso claramente honesto (José) &, 000 \\
& &, 000 \\
(C) Adequação da citação & $-6,473$ \\
(C1) Caso cinzento (Henrique) - p < 0,001 & $-4,331$ & \\
(C2) Caso claramente honesto (Paulo) & &, 000 \\
& &, 873 \\
(D) Submissão de uma tarefa não inédita & $-9,395$ &,- 160 \\
(D1) Caso cinzento (André) - p < 0,001 & & \\
(D2) Caso claramente desonesto (Patrícia) & & \\
\end{tabular}


Nota: Avaliação da Honestidade ( -2 = Desonesto; 2 = Honesto $)$

Fonte: Elaborado pelos autores deste artigo com dados da pesquisa.

Os resultados da avaliação das penalidades mostram as diferenças entre as penalidades dos alunos em relação às penalidades dos professores na visão dos alunos. A avaliação dos alunos mostrou diferenças significativas em nove dos dez casos, conforme Tabela 6. Os alunos acreditam que existem diferenças nas avaliações dos alunos e dos professores. Nesses casos, os alunos acham que os professores dariam uma penalidade maior que os alunos. Penalidade maior significa mais severa. Os resultados foram obtidos por meio das diferenças entre penalidade dos alunos versus penalidade dos professores na visão dos alunos, usando-se o teste não paramétrico de Wilcoxon para amostras pareadas com $p \leq 0,05$. Esse resultado é consistente com a hipótese H2a-Penalidade aluno, em que as penalidades impostas pelos alunos serão menos rigorosas que as penalidades dos professores na visão dos alunos.

Analisando-se os casos cinzentos, observa-se que, em todos os casos, houve diferença significativa e, em todos eles, os alunos deram uma penalidade menos severa do que eles acham que os professores dariam. Os resultados são similares ao estudo americano em que, em todas as situações, foram observadas diferenças significativas. Já no trabalho brasileiro, a diferença é maior, pois ocorreu diferença significativa em apenas dois dos oito casos.

Tabela 6 - Diferenças entre penalidade dos alunos versus penalidade dos professores na visão dos alunos

\begin{tabular}{lcr}
\hline Casos & $\mathbf{Z}$ & $\mathbf{p}$ \\
\hline (A) Passar informação de exames já realizados & & \\
(A1) Caso cinzento (Ana) & $-8,422$ &, 000 \\
(A2) Caso cinzento (Luís) & $-8,932$ &, 000 \\
(A3) Caso claramente desonesto (Edson) & $-4,541$ &, 000 \\
(A4) Caso claramente desonesto (Breno) & $-5,613$ &, 000 \\
& & \\
(B) Trabalho em grupo & $-7,764$ &, 000 \\
(B1) Caso cinzento (Diego) & $-2,380$ &, 017 \\
(B2) Caso claramente honesto (José) & & \\
& & \\
(C) Adequação da citação & $-4,769$ &, 000 \\
(C1) Caso cinzento (Henrique) & $-1,277$ &, 202 \\
(C2) Caso claramente honesto (Paulo) & & \\
& &, 000 \\
(D) Submissão de uma tarefa não inédita & $-8,316$ &, 000 \\
(D1) Caso cinzento (André) & $-3,698$ & \\
(D2) Caso claramente desonesto (Patrícia)
\end{tabular}

Nota: Penalidade ( 1 = Sem penalidade; 5 = Penalidade severa)

Fonte: Elaborado pelos autores deste artigo com dados da pesquisa. 
Verificou-se também se o professor tem ideia de como os alunos avaliam um mesmo caso. As diferenças significativas entre avaliação do professor e avaliação do aluno na visão do professor ocorreram em seis dos oito casos (Tabela 7). Os resultados foram obtidos por meio das diferenças entre a avaliação dos professores e avaliação dos alunos na visão dos professores, usando-se o teste não paramétrico de Wilcoxon para amostras pareadas com $\mathrm{p} \leq$ 0,05 para os oito casos presentes na pesquisa. $\mathrm{Na}$ maior parte dos casos, os professores acreditam que os alunos avaliam de modo diferente. Em todos os casos com diferenças significativas, os professores acham que os alunos dariam nota maior em relação à honestidade acadêmica. Nota maior significa achar o caso mais honesto. Os professores concordam que a avaliação deles é mais rigorosa que a dos alunos. É a mesma percepção que os alunos têm em relação à avaliação do professor na hipótese anterior. Esses resultados são consistentes com a hipótese H2b - Honestidade professor, em que as avaliações dos professores serão mais rigorosas que as avaliações dos alunos na visão dos professores. Os resultados são similares com o trabalho original americano, em que, em todas as situações, foram observadas diferenças significativas.

Tabela 7 - Diferenças entre avaliação dos professores versus avaliação dos alunos na visão dos professores

\begin{tabular}{lrr}
\hline Casos & $\mathbf{Z}$ & $\mathbf{p}$ \\
\hline (A) Passar informação de exames já realizados & &, 002 \\
(A1) Caso cinzento (Ana e Luís) & $-3,100$ &, 004 \\
(A2) Caso claramente desonesto (Edson e Breno) & $-2,844$ &, 003 \\
& &, 111 \\
(B) Trabalho em grupo & $-2,969$ & \\
(B1) Caso cinzento (Diego) - p < 0,001 & $-1,594$ &, 012 \\
(B2) Caso claramente honesto (José) & 1,000 \\
& & \\
(C) Adequação da citação & $-2,521$ &, 000 \\
(C1) Caso cinzento (Henrique) - p < 0,001 & \\
(C2) Caso claramente honesto (Paulo) & $-3,211$ \\
& $-2,401$ \\
(D) Submissão de uma tarefa não inédita &, 016 \\
(D1) Caso cinzento (André) - p < 0,001 & & \\
(D2) Caso claramente desonesto (Patrícia)
\end{tabular}

Nota: Avaliação da Honestidade (-2 = Desonesto; 2 = Honesto)

Fonte: Elaborado pelos autores deste artigo com dados da pesquisa.

Os resultados da avaliação das penalidades mostraram as diferenças entre as penalidades dos alunos em relação às penalidades dos professores na visão do professor, como observado na Tabela 8. Houve diferenças significativas em sete dos dez casos. Nesses casos, os professores acham que os alunos dariam penalidades menos severas que os 
professores. Os resultados foram obtidos por meio das diferenças entre penalidade dos professores versus penalidade dos alunos na visão dos professores, usando-se o teste não paramétrico de Wilcoxon para amostras pareadas com $\mathrm{p} \leq 0,05$. Esse resultado é consistente com a hipótese $H 2 b$ - penalidade professor, em que as penalidades impostas pelos professores serão mais rigorosas que as penalidades dos alunos na visão dos professores. Os resultados são similares com o trabalho original, em que, em todas as situações, foram observadas diferenças significativas.

Tabela 8 - Diferenças entre a penalidade dos professores versus penalidade dos alunos na visão dos professores

\begin{tabular}{lcr}
\hline Casos & $\mathbf{Z}$ & $\mathbf{p}$ \\
\hline (A) Passar informação de exames já realizados & &, 066 \\
(A1) Caso cinzento (Ana) & $-1,841$ &, 066 \\
(A2) Caso cinzento (Luís) & $-1,841$ &, 007 \\
(A3) Caso claramente desonesto (Edson) & $-2,687$ &, 004 \\
(A4) Caso claramente desonesto (Breno) & $-2,844$ & \\
& &, 004 \\
(B) Trabalho em grupo & $-2,877$ \\
(B1) Caso cinzento (Diego) & $-2,060$ &, 039 \\
(B2) Caso claramente honesto (José) & & \\
& & \\
(C) Adequação da citação & $-2,437$ &, 015 \\
(C1) Caso cinzento (Henrique) & $-1,000$ &, 317 \\
(C2) Caso claramente honesto (Paulo) & & \\
(D) Submissão de uma tarefa não inédita & $-3,372$ &, 001 \\
(D1) Caso cinzento (André) & $-2,850$ &, 004 \\
\hline (D2) Caso claramente desonesto (Patrícia)
\end{tabular}

Nota: Penalidade $(1=$ Sem penalidade; 5 = Penalidade severa $)$

Fonte: Elaborado pelos autores deste artigo com dados da pesquisa.

\subsection{Precisões da percepção dos alunos e professores}

A precisão de ambos os grupos (alunos e professores) em relação à percepção do outro grupo foi realizada comparando a visão do outro grupo com sua própria avaliação, por exemplo, comparando a avaliação do aluno com a visão do aluno pelo professor (alunoaluno). Essa mensuração tem como objetivo detalhar a diferença percebida de alunos e professores em relação à avaliação do outro grupo.

O resultado para a precisão da visão dos alunos para a avaliação dos professores foi obtido por meio das diferenças entre avaliação real dos professores e a avaliação do professor na visão do aluno, usando-se o teste não paramétrico de Mann-Whitney para amostras independentes com $\mathrm{p} \leq 0,05$. 
Os dados coletados indicam que apenas três dos oito casos mostraram diferenças significativas entre as avaliações dos professores na visão dos alunos e a avaliação real do professor (TAB. 9). 
Tabela 9 - Diferenças entre avaliação dos alunos real versus avaliação dos alunos na visão dos professores

\begin{tabular}{lcr}
\hline Casos & $\mathbf{Z}$ & $\mathbf{P}$ \\
\hline (A) Passar informação de exames já realizados & & \\
(A1) Caso cinzento (Ana e Luís) & $-2,776$ &, 006 \\
$\quad$ (A2) Caso claramente desonesto (Edson e Breno) & $-3,224$ &, 001 \\
& & \\
(B) Trabalho em grupo & $-1,135$ &, 256 \\
$\quad$ (B1) Caso cinzento (Diego) -- p < 0,001 &,- 255 &, 799 \\
$\quad$ (B2) Caso claramente honesto (José) & & \\
& & \\
(C) Adequação da citação &,- 195 &, 846 \\
(C1) Caso cinzento (Henrique) - p <0,001 &,- 786 &, 432 \\
(C2) Caso claramente honesto (Paulo) & & \\
& & \\
(D) Submissão de uma tarefa não inédita & $-1,291$ &, 197 \\
$\quad$ (D1) Caso cinzento (André) - p < 0,001 & $-3,137$ &, 002 \\
\hline (D2) Caso claramente desonesto (Patrícia)
\end{tabular}

Nota: Avaliação da Honestidade ( 2 = Desonesto; 2 = Honesto)

Fonte: Elaborado pelos autores deste artigo com dados da pesquisa.

Na maior parte dos casos não se pode afirmar que existem diferenças significativas, o que indica que as visões dos alunos são relativamente precisas. Nos três casos, os alunos veem os professores como mais severos do que realmente são. Os alunos dão maior nota ao professor do que o próprio professor. Esses resultados são consistentes com a hipótese $H 3 a-$ Honestidade aluno, em que os alunos perceberão as avaliações dos professores, em relação à honestidade acadêmica, como sendo mais rigorosas do que elas realmente são.

O resultado para a precisão da visão dos professores foi obtido por meio das diferenças entre avaliação real dos alunos e a avaliação do aluno na visão dos professores, usando-se o teste não paramétrico de Mann-Whitney para amostras independentes com $p \leq 0,05$.

Os dados coletados indicam que apenas três dos oito casos mostraram diferenças significativas entre as avaliações dos alunos na visão dos professores e a avaliação real dos alunos (TAB. 10). Na maior parte dos casos, não é possível afirmar que existem diferenças significativas, o que indica que os professores são relativamente precisos. Nos três casos, os professores acham que os alunos julgam os casos mais honestos do que eles realmente são. A precisão dos alunos é comparável à precisão dos professores. Esses resultados são consistentes com a hipótese H3b - Honestidade professor, em que os professores perceberão as avaliações dos alunos, em relação à honestidade acadêmica, como sendo menos rigorosas do que elas realmente são. 
Tabela 10 - Diferenças entre avaliação dos professores real versus avaliação dos professores na visão dos alunos

\begin{tabular}{lrr}
\hline Casos & $\mathbf{Z}$ & $\mathbf{p}$ \\
\hline (A) Passar informação de exames já realizados & &, 257 \\
$\quad$ (A1) Caso cinzento (Ana e Luís) & $-1,132$ &, 794 \\
(A2) Caso claramente desonesto (Edson e Breno) &,- 262 & \\
& &, 007 \\
(B) Trabalho em grupo & $-2,684$ &, 430 \\
$\quad$ (B1) Caso cinzento (Diego) - p < 0,001 &,- 790 & \\
$\quad$ (B2) Caso claramente honesto (José) & &, 003 \\
& &, 222 \\
(C) Adequação da citação & $-2,989$ & \\
(C1) Caso cinzento (Henrique) - p < 0,001 & $-1,221$ & \\
(C2) Caso claramente honesto (Paulo) & &, 002 \\
(D) Submissão de uma tarefa não inédita & &, 203 \\
\hline (D1) Caso cinzento (André) - p < 0,001 \\
(D2) Caso claramente desonesto (Patrícia)
\end{tabular}

Nota: Avaliação da Honestidade (-2 = Desonesto; 2 = Honesto)

Fonte: Elaborado pelos autores deste artigo com dados da pesquisa.

\subsection{Existência de diferenças nas avaliações atribuídas pelos alunos acerca da honestidade acadêmica considerando apenas o gênero}

Foi observada apenas uma diferença significativa para o grupo de alunos da amostra pesquisada, de acordo com a Tabela 11, se considerado o gênero. O resultado foi obtido por meio das diferenças entre avaliação dos alunos de ambos os gêneros para os oito casos da pesquisa, usando-se o teste não paramétrico de Mann-Whitney com $\mathrm{p} \leq 0,05$.

Tabela 11 - Diferenças nas avaliações dos alunos considerando o gênero

\begin{tabular}{lcr}
\hline Casos & $\mathbf{Z}$ & $\mathbf{p}$ \\
\hline (A) Passar informação de exames já realizados & &, 460 \\
(A1) Caso cinzento (Ana e Luís) &,- 739 &, 553 \\
(A2) Caso claramente desonesto (Edson e Breno) &,- 593 & \\
& & \\
(B) Trabalho em grupo & $-2,022$ &, 043 \\
$\quad$ (B1) Caso cinzento (Diego) &,- 731 &, 465 \\
(B2) Caso claramente honesto (José) & & \\
&,- 396 &, 692 \\
(C) Adequação da citação &,- 275 &, 783 \\
(C1) Caso cinzento (Henrique) & & \\
(C2) Caso claramente honesto (Paulo) & & \\
& $-1,217$ &, 224 \\
(D) Submissão de uma tarefa não inédita & $-1,341$ &, 180 \\
(D1) Caso cinzento (André) & & \\
(D2) Caso claramente desonesto (Patrícia)
\end{tabular}

Nota: Avaliação da Honestidade (-2 = Desonesto; 2 = Honesto)

Fonte: Elaborado pelos autores deste artigo com dados da pesquisa. 
Nesse único caso que se refere ao caso de trabalho em grupo, as alunas apresentaram valores superiores, ou seja, consideram o caso mais honesto que os alunos. Esse resultado é inconsistente com a hipótese H4 - gênero aluno, em que as alunas classificarão as situações, envolvendo comportamentos acadêmicos questionáveis, como sendo mais rigorosas que a avaliação feita pelos alunos.

\subsection{Existência de diferenças nas avaliações realizadas pelos professores acerca da honestidade acadêmica considerando apenas o gênero}

Foi observada, também, apenas uma diferença significativa para o grupo de professores da amostra pesquisada, considerando-se o gênero (TAB. 12). O resultado foi obtido por meio das diferenças entre avaliação dos professores de ambos os gêneros para os oito casos da pesquisa, usando-se o teste não paramétrico de Mann-Whitney com $\mathrm{p} \leq 0,05$.

\section{Tabela 12 - Diferenças entre avaliação dos professores considerando o gênero}

\begin{tabular}{lrr}
\hline Casos & $\mathbf{Z}$ & $\mathbf{p}$ \\
\hline (A) Passar informação de exames já realizados & &, 964 \\
(A1) Caso cinzento (Ana) &,- 046 &, 723 \\
(A2) Caso cinzento (Luís) &,- 355 &, 334 \\
(A3) Caso claramente desonesto (Edson) &,- 965 &, 135 \\
(A4) Caso claramente desonesto (Breno) & $-1,493$ & \\
& &, 541 \\
(B) Trabalho em grupo &,- 612 &, 035 \\
(B1) Caso cinzento (Diego) & $-2,107$ & \\
(B2) Caso claramente honesto (José) & &, 783 \\
& &, 296 \\
(C) Adequação da citação &,- 275 & \\
(C1) Caso cinzento (Henrique) & $-1,046$ &, 560 \\
(C2) Caso claramente honesto (Paulo) & &, 843 \\
(D) Submissão de uma tarefa não inédita &,- 583 & \\
(D1) Caso cinzento (André) &,- 199 & \\
(D2) Caso claramente desonesto (Patrícia) & & \\
\hline
\end{tabular}

Nota: Avaliação da Honestidade ( -2 = Desonesto; 2 = Honesto)

Fonte: Elaborado pelos autores deste artigo com dados da pesquisa.

Esse resultado é inconsistente com a hipótese $H 4$ - gênero professor, em que as professoras classificarão as situações, envolvendo comportamentos acadêmicos questionáveis, como sendo mais rigorosas que a avaliação feita pelos professores. 


\subsection{Existência de diferenças nas avaliações realizadas pelos alunos acerca da honestidade acadêmica considerando-se apenas a faixa etária}

Foram observadas diferenças significativas em apenas dois dos oito casos para o grupo de alunos da amostra pesquisada se considerada a faixa etária (TAB. 13). O resultado foi obtido por meio das diferenças entre avaliação dos alunos de diversas idades para os oito casos da pesquisa, usando-se o teste não paramétrico de Kruskal-Wallis com $p \leq 0,05$.

No primeiro caso cinzento formalizado por "Passar informações de exames já realizados", ocorreu diferença significativa entre os alunos, se considerada a faixa etária. Pelo teste post hoc de Dunn, tem-se que a faixa de 17 a 25 anos teve valores significativamente inferiores, ou seja, considera o caso mais desonesto, em relação às demais faixas etárias. Nesse caso os alunos mais novos são mais rigorosos.

No caso claramente desonesto indicado por "Submissão de uma tarefa não inédita", ocorreu uma diferença significativa entre os alunos, se considerada a faixa etária. Pelo teste post hoc de Dunn, tem-se que a faixa etária de mais de 26 anos teve valores significativamente inferiores às faixas de idade entre 17 e 25 anos. Isso significa que a faixa etária mais velha dos alunos considera o caso mais desonesto que as demais faixas

Tabela 13 - Honestidade acadêmica entre alunos de diferentes faixas etárias

\begin{tabular}{lrr}
\hline Casos & Chi-Square & p \\
\hline (A) Passar informação de exames já realizados & &, 005 \\
(A1) Caso cinzento (Ana e Luís) & 14,971 &, 065 \\
(A2) Caso claramente desonesto (Edson e Breno) & 8,843 & \\
& & \\
(B) Trabalho em grupo & 7,764 &, 101 \\
(B1) Caso cinzento (Diego) & 1,796 &, 773 \\
(B2) Caso claramente honesto (José) & & \\
& &, 074 \\
(C) Adequação da citação & 8,546 &, 884 \\
(C1) Caso cinzento (Henrique) & 1,165 & \\
(C2) Caso claramente honesto (Paulo) & & \\
& &, 489 \\
(D) Submissão de uma tarefa não inédita & 3,429 &, 012 \\
(D1) Caso cinzento (André) & 12,882 & \\
(D2) Caso claramente desonesto (Patrícia) & &
\end{tabular}

Nota: Avaliação da Honestidade ( 2 = Desonesto; 2 = Honesto)

Fonte: Elaborado pelos autores deste artigo com dados da pesquisa.

Esse resultado é inconsistente com a hipótese $H 5$ - idade aluno, em que os alunos (de ambos os gêneros) com maior idade classificarão as situações, envolvendo comportamentos 
acadêmicos questionáveis, como sendo mais desonestos que a avaliação feita pelos alunos de menor idade.

\subsection{Existência de diferenças nas avaliações realizadas pelos professores acerca da honestidade acadêmica considerando-se apenas a faixa etária}

Não foi observada nenhuma diferença significativa para o grupo de professores da amostra pesquisada considerando-se a faixa etária. O resultado foi obtido por meio das diferenças entre avaliação dos professores de duas categorias (até 40 anos e acima de 40 anos) para os oito casos da pesquisa, usando-se o teste não paramétrico de Mann-Whitney com $\mathrm{p} \leq$ 0,05 .

Tabela 14 - Honestidade acadêmica entre professores de diferentes faixas etárias

\begin{tabular}{lrr}
\hline Casos & $\mathbf{Z}$ & $\mathbf{p}$ \\
\hline (A) Passar informação de exames já realizados & &, 479 \\
(A1) Caso cinzento (Ana e Luís) &, 228 \\
(A2) Caso claramente desonesto (Edson e Breno) & $-1,206$ \\
& & \\
(B) Trabalho em grupo &,- 851 &, 395 \\
(B1) Caso cinzento (Diego) &,- 303 \\
(B2) Caso claramente honesto (José) &, 762 \\
& \\
(C) Adequação da citação &, 0999 \\
(C1) Caso cinzento (Henrique) & 9999 \\
(C2) Caso claramente honesto (Paulo) & 1,000 \\
& & \\
(D) Submissão de uma tarefa não inédita & $-1,100$ \\
(D1) Caso cinzento (André) &,- 837 \\
(D2) Caso claramente desonesto (Patrícia) &, 403 \\
\hline
\end{tabular}

Nota: Avaliação da Honestidade (-2 = Desonesto; 2 = Honesto)

Fonte: Elaborado pelos autores deste artigo com dados da pesquisa.

Esse resultado é inconsistente com a hipótese $H 5$ - idade professor, em que os professores (de ambos os gêneros) com maior idade classificarão as situações, envolvendo comportamentos acadêmicos questionáveis, como sendo mais desonestos que a avaliação feita pelos professores de menor idade.

\section{CONCLUSÃO}

Ao descrever a percepção dos discentes e docentes de um curso de graduação em ciências contábeis acerca da honestidade acadêmica, acredita-se que é possível provocar 
maior discussão acerca da honestidade acadêmica e o respeito ao código de ética. Isso se torna ainda mais relevante se consideradas as recentes fraudes contábeis no Brasil e no mundo.

Para responder à primeira questão de pesquisa, que analisa as diferenças entre as avaliações de alunos e professores em relação à honestidade acadêmica, constatou-se que a hipótese deve ser rejeitada já que apenas em quatro dos oito casos ocorreram diferenças significativas. As diferenças ocorreram apenas para os casos cinzentos. Nos casos mais claros, não existe diferença significativa entre a percepção dos professores e alunos em relação à honestidade acadêmica. Comparando-se com a amostra brasileira e americana, constatou-se que os resultados desta pesquisa estão mais próximos dos resultados da pesquisa americana do que da brasileira.

A segunda questão de pesquisa trata da percepção dos alunos em relação à avaliação e penalidade do professor e da percepção dos professores em relação à avaliação e penalidade do aluno. No que se refere à percepção dos alunos em relação à avaliação e penalidade do professor, as hipóteses não foram rejeitadas. Isso significa que os alunos acreditam que existe essa diferença de percepção para a honestidade acadêmica e para penalidade. $\mathrm{O}$ aluno acha que o professor será mais severo que o aluno, o que ocorreu também nas duas pesquisas anteriores.

Com relação à percepção dos professores em relação à avaliação e penalidade do aluno, as hipóteses não foram rejeitadas. Isso significa que os professores acreditam que existe essa diferença de percepção para a honestidade acadêmica e para penalidade. Os professores percebem que são mais rigorosos que os alunos. Esse resultado se aproxima mais da pesquisa americana, em que foram encontradas diferenças em todos os casos, do que da brasileira, em que apenas três dos oito casos apresentaram diferenças significativas. Essa diferença de percepção pode diminuir caso o processo de comunicação entre os alunos e os professores se torne mais eficaz.

A terceira questão de pesquisa trata da precisão da visão do aluno e do professor em relação ao outro. Constatou-se que tanto o professor como o aluno são igualmente precisos em suas visões. Comparando-os com a amostra brasileira e americana, verifica-se que os alunos desta pesquisa são menos precisos que os da pesquisa brasileira e americana. Já os professores desta pesquisa são mais precisos que os da pesquisa brasileira e americana.

A quarta e a quinta questões de pesquisa tratam do impacto do gênero e da idade na avaliação da honestidade acadêmica. Ambas as hipóteses foram rejeitadas, sinalizando que 
não é possível afirmar que existem diferenças significativas de percepção da honestidade acadêmica para esta amostra se considerados o gênero e a idade. Isso pode indicar que essas variáveis não têm muito impacto na percepção da honestidade acadêmica.

$\mathrm{Na}$ sexta e última questão de pesquisa verifica-se se as categorias impactam, de forma uniforme, a percepção da honestidade acadêmica. A hipótese não foi rejeitada. Esse resultado é consistente com os resultados encontrados nas pesquisas americana e brasileira.

No Quadro 2 resumem-se as questões de pesquisa, bem como os resultados obtidos para as hipóteses testadas.

\section{Quadro 2 - Resumo das hipóteses e resultados}

\begin{tabular}{|c|l|c|c|c|c|}
\hline \multicolumn{2}{|c|}{ Questões resumidas } & $\begin{array}{l}\text { Hipóteses } \\
\text { Honestidade }\end{array}$ & Resultados & $\begin{array}{l}\text { Hipóteses } \\
\text { Penalidade }\end{array}$ & Resultados \\
\hline 1 & $\begin{array}{l}\text { Existem diferenças na avaliação da } \\
\text { honestidade acadêmica entre alunos e } \\
\text { professores? }\end{array}$ & H1 & $\begin{array}{c}\text { Rejeitada } \\
\text { (não rejeitada } \\
\text { só em casos } \\
\text { cinzentos) }\end{array}$ & H1 & Rejeitada \\
\hline $2 \mathrm{a}$ & $\begin{array}{l}\text { Alunos acham que avaliam diferente dos } \\
\text { professores? }\end{array}$ & $\mathrm{H} 2 \mathrm{a}$ & Não rejeitada & $\mathrm{H} 2 \mathrm{a}$ & $\begin{array}{c}\text { Não } \\
\text { rejeitada }\end{array}$ \\
\hline 2b & $\begin{array}{l}\text { Professores acham que avaliam diferente } \\
\text { dos alunos? }\end{array}$ & $\mathrm{H} 2 \mathrm{~b}$ & Não rejeitada & $\mathrm{H} 2 \mathrm{~b}$ & $\begin{array}{c}\text { Não } \\
\text { rejeitada }\end{array}$ \\
\hline 3a & A avaliação dos alunos é precisa? & $\mathrm{H} 3 \mathrm{a}$ & Não rejeitada & - & - \\
\hline 3b & A avaliação dos professores é precisa? & $\mathrm{H} 3 \mathrm{~b}$ & Não rejeitada & - & - \\
\hline $4 \mathrm{a}$ & $\begin{array}{l}\text { Existem diferenças considerando o gênero } \\
\text { dos alunos? }\end{array}$ & $\mathrm{H} 4 \mathrm{a}$ & Rejeitada & - & - \\
\hline 4b & $\begin{array}{l}\text { Existem diferenças considerando o gênero } \\
\text { dos professores? }\end{array}$ & $\mathrm{H} 4 \mathrm{~b}$ & Rejeitada & - & - \\
\hline 5a & $\begin{array}{l}\text { Existem diferenças considerando a idade } \\
\text { dos alunos? }\end{array}$ & $\mathrm{H} 5 \mathrm{a}$ & Rejeitada & - & - \\
\hline $5 \mathrm{~b}$ & $\begin{array}{l}\text { Existem diferenças considerando a idade } \\
\text { dos professores? }\end{array}$ & $\mathrm{H} 5 \mathrm{~b}$ & Rejeitada & - & - \\
\hline 6 & $\begin{array}{l}\text { Existe uniformidade em relação aos tipos } \\
\text { de casos apresentados? }\end{array}$ & $\mathrm{H} 6$ & Não rejeitada & - & - \\
\hline
\end{tabular}

Fonte: Elaborado pelos autores deste artigo com dados da pesquisa.

Este trabalho permitiu avançar na pesquisa acerca da honestidade acadêmica uma vez que foi possível identificar o "gap" entre os alunos e professores acerca da honestidade acadêmica em uma instituição de ensino pública de um importante estado brasileiro.

Foi observado que as diferenças são significativas para a avaliação e as penalidades acerca da honestidade acadêmica apenas para os "casos cinzentos", evidenciando-se que os alunos e professores têm uma percepção de avaliação dos respectivos alunos e professores diferente da realidade. 
Neste estudo foram incluídas as variáveis gênero e idade para análise da percepção dos alunos e professores sobre a honestidade acadêmica, não presentes nos estudos americano e brasileiro anteriores, porém não foi verificado impacto dessas variáveis na percepção acerca da honestidade acadêmica.

Os resultados obtidos por meio do questionário aqui proposto podem ser utilizados para elaborar estratégias particulares para cada instituição no que diz respeito à discussão da honestidade acadêmica junto a seus alunos e futuros profissionais. Esses resultados possibilitam fomentar novas discussões dentro da sala de aula sobre a honestidade acadêmica e seus potenciais reflexos na conduta ética profissional no mercado de trabalho.

Acredita-se que as diferenças encontradas entre as pesquisas podem ser culturais, o que leva a interpretações do código de ética de forma diferente. Novos estudos devem ser realizados para confirmar esses resultados. $\mathrm{O}$ resultado desta pesquisa está limitado à amostra de alunos e professores de uma universidade pública do Brasil. 


\section{REFERÊNCIAS}

ANJOS, L. C. M. et al. Código de Ética e o Comportamento ético na vida pessoal: um estudo junto a pessoas envolvidas com a Contabilidade. Revista de Contabilidade da UFBA, v. 5, n. 2, p. 4-19, maio/ago. 2011.

ASHWORTH, P.; BANNISTER, P. Guilty in whose eyes? University student's perceptions of cheating and plagiarism in academic work and assessment. Studies in Higher Education, v. 22, Issue 2, 1 chart, jun. 1997.

BARBASTEFANO, R. G.; SOUZA, C. G. Percepção do conceito de plágio acadêmico entre alunos de engenharia de produção e ações para sua redução. Revista Produção Online, edição especial, dez. 2007.

BITTAR, E. C.B. Curso de Ética Jurídica - Ética Geral e Profissional. 5. ed. São Paulo: Saraiva, 2007.

BORGES, E.; MEDEIROS, C. Comprometimento e Ética Profissional: um estudo de suas relações junto aos contabilistas. Revista Contabilidade \& Finanças. São Paulo, n. 44, p. 6071, maio/ago. 2007.

BRASIL. Ministério da Educação. Disponível em: <http://emec.mec.gov.br〉. Acesso em: 25 fev. 2013.

BRAUN, R. L.; STALLWORTH, H. L.; CRAM, D. P. The Academic Honesty

Expectations Gap: An Analysis of Student and Faculty Perspectives. Working Paper, 2005.

CAMARGO, M. Fundamentos de Ética Geral e Profissional. Petrópolis: Vozes, 1999.

CAVALCANTI, C. C. Desonestidade acadêmica em cursos superiores à distância. In: Congresso ABED, 2008. Disponível em:

<http://www.abed.org.br/congresso2008/tc/54200865734PM.pdf>. Acesso em: 18 jan. 2013.

CONSELHO FEDERAL DE CONTABILIDADE. Disponível em: <http://www.cfc.org.br>. Acesso em: 25 fev. 2013.

CROWN, D. F.; SPILLER, M. S. Learning from the Literature on Collegiate Cheating: A Review of Empirical Research. Journal of Business Ethics, v. 17, p. 683-700, 1998.

FORTES, J. C. Manual do Contabilista. São Paulo: Saraiva, 2005.

GIL, A. C. Como elaborar projetos de pesquisa. São Paulo: Atlas, 2006.

JOHNS, S. K.; STRAND, C. A. Survey Results of the Ethical Beliefs of Business Students. Journal of Education for Business, p. 315-320, jul./aug., 2000.

LAMBERT, E. G.; HOGAN, N. L.; BARTON, S. M. Collegiate Academic Dishonesty Revisited: What Have They Done, How Often Have They Done It, Who Does It, And Why Did They Do It? Electronic Journal of Sociology, 2003.

LISBOA, L. P. et al. Ética Geral e Profissional em Contabilidade. 2. ed. São Paulo: Atlas, 1997.

MARTINS, G. A.; THEÓPHILO, C. R. Metodologia da Investigação Científica para

Ciências Sociais Aplicadas. São Paulo: Atlas, 2007. 
NEWSTEAD, S. E.; FRANKLYN-STOKES A.; ARMSTEAD, P. Individual Differences in Student Cheating. Journal of Educational Psychology, v. 88, n. 2, p. 229-241, 1996.

NONIS, S.; SWIFT, C. O. An examination of the relationship between academic dishonesty and workplace dishonesty: a multicampus investigation. Journal of Education for Business, v. 77, n. 2, p. 69-77, 2001.

OLIVEIRA NETO, J. D.; CHACAROLLI, O. A honestidade acadêmica de professores e alunos de contabilidade. In: CONGRESSO USP DE CONTROLADORIA E CONTABILIDADE, 10, 2010. São Paulo, Anais... São Paulo: USP, 2012. Disponível em: <http://www.congressousp.fipecafi.org/artigos102010/578.pdf>. Acesso em: 15 dez. 2012.

PAVELA, G. Applying the power of association on Campus: A model code of academic integrity. Journal of College and University Law, v. 24, n. 1, p. 1-22, 1978.

SILVA, O. S. F. Entre o plágio e a autoria: qual o papel da universidade? Revista Brasileira de Educação, v. 13, n. 38, p. 357-368, maio/ago. 2008.

SIMON, C. A. et al. Gender, student perceptions, institutional commitments and academic dishonesty: who reports in academic dishonesty cases? Assessment \& Evaluation in Higher Education, v. 29, n. 1, p. 75-90, feb. 2004.

SMITH, J.; NOLAN, R.; DAI, Y. Faculty perceptions of student academic honesty. College Student Journal, v. 32, n. 2, p. 305-310, 1998.

VÁSQUEZ, A. S. Ética. 11. ed. Rio de Janeiro: Civilização Brasileira. 1987. 